\title{
УСКОРЕННОЕ РАЗВИТИЕ
}

\section{МИКРОЭЛЕКТРОНИКИ И ИКТ}

\section{И ЧЕТВЕРТАЯ ПРОМЫШЛЕННАЯ \\ РЕВОЛЮЦИЯ}

О.Кошовец, к.филос.н. ${ }^{1}$, Н.Ганичев, к.э.н.. ${ }^{2}$

УДК 004.3:330.3

BAK 05.13 .00

\author{
Финансовый кризис 2007-2009 годов и спровоцированная \\ им так называемая "великая рецессия", то есть стагнация \\ развития мировой экономики, наглядно продемонстрировали \\ несостоятельность и прогностическую дисфункцию доминирующей \\ экономической теории (мейнстрима), которая оказалась \\ неспособна ни предсказать, ни объяснить эти процессы [1, 2, 3]. \\ На этом фоне весьма востребованными оказались такие концепции \\ и идеи, которые могли бы предложить новые механизмы роста, \\ при этом особое внимание было обращено на технологические \\ новации, которые на протяжении 20 века продемонстрировали \\ способность продуцировать быстрый экономический рост $[4,5]$.
}

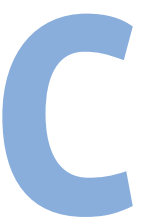

огласно теории о технологических укладах в экономическом развитии выделяют жизненные циклы пяти таких укладов [6]. Базисным нововведением (или "технологией общего назначения") для последнего из циклов, начавшего формироваться во второй половине 20 века, стала радиоэлектроника и развитие на ее основе инфокоммуникационных технологий (ИКТ). В 1950-1990 годах произошел стремительный технологический рывок в сфере производства радиоэлектронного оборудования, начавшийся, как и большинство технологических нововведений, с оборонных заказов [7]. Превращение микроэлектроники в "технологию общего назначения", имеющую очень широкую область

1 ИНПРАН, ИЭРАН, старший научныЙ сотрудник, helzerr@yandex.ru.

ИНП РАН, научный сотрудник, nickgan@yandex.ru. применения и способную порождать целое древо новых технологий, сделало ее драйвером экономического роста на долгие годы. Это произошло благодаря тому, что микроэлектроника, по сути, стала первой успешно коммерциализированной высокотехнологичной отраслью, в кратчайшие сроки сформировавшей огромный потребительский рынок. При этом бурному развитию микроэлектроники, с одной стороны, способствовал избыток финансовых ресурсов и особенности функционирования американской финансовой системы, а с другой - потребительский послевоенный бум в США, на фоне которого начал формироваться так называемый "средний класс", ставший основой современного "общества потребления". Совокупность этих факторов привела к тому, что в 1970-е годы массовые инвестиции в инновационные проекты в области радиоэлектроники стали коммерчески 
выгодными. Возникла и укрепилась новая форма движения капитала, получившая наименование венчурного капитала, которая, в свою очередь, дала новый импульс развития технологическим инновациям [8].

К концу 20 века сформировалась целая группа основанных на электронике и ИКТ технологических совокупностей, опирающаяся на новые финансовые инструменты. Причем с 1990-х годов решающую роль в их развитии стали играть не только и не столько технологические инновации в области микроэлектроники, сколько новые формы услуг, основанные на ИКТ. Вторая половина 1990-х и начало 2000-х годов стали периодом формирования новой глобальной волны инноваций не просто в области технического совершенствования микроэлектроники, но прежде всего на рынке услуг, для которых микроэлектроника стала инфраструктурой развития. Эти высокотехнологичные услуги, в свою очередь, стали оказывать мощное обратное воздействие (через предъявление новых требований к оборудованию) на аппаратную составляющую ИКТ [9].

Между тем, так называемый "кризис доткомов" в начале 2000-2001 годов, когда котировки акций ведущих высокотехнологичных компаний (NASDAQ Composite) упали почти на 80\%, продемонстрировал, что этот бурный рост был во многом не экономическим, а чисто финансовым явлением. Оказалось, что высокие темпы роста поддерживались за счет "псевдо-инноваций" из области маркетинга и завышенных ожиданий инвесторов, активно подогреваемых многочисленными экспертами и экономистами, утверждавшими, что наступила эра "новой экономики", в которой ключевую роль будут играть нематериальные активы. Однако по итогам кризиса начала 2000-х годов фактически прекратил свое существование целый сектор услуг, востребованность и ценность которых оказалась "раздутой" за счет спекулятивных операций с ценными бумагами, проводимых инвесторами, убежденными в начале формирования новой пост-индустриальной эпохи [10].

Во второй половине 2000-х годов наметились признаки насыщения на рынках услуг мобильной связи, что дало ряду исследователей повод говорить об исчерпании механизмов экономического роста в рамках пятого технологического уклада. Следует отметить, что в начале 2000-х годов и непосредственно в преддверии кризиса 2007-2009 годов основные надежды на новую технологическую революцию связывали сначала с биотехнологиями, затем с нанотехнологиями, и, наконец, с конвергенцией нано-, био-, информационных и когнитивных технологий, а также робототехники (NBRIC). Так, с нанотехнологиями связывали формирование новой экономики и кардинальное преобразование большинства отраслей. Однако в целом рынки нанотехнологий развивались по схемам, похожим на развитие рынков интернет-компаний в конце 1990-х годов, то есть при активном участии фондовых рынков, продававших акции многочисленных компаний с приставкой "нано" в названии, однако имеющих весьма условное или отдаленное отношение к нанотехнологиям. Этой "технологической революции" помешал кризис 2007-2009 годов [11, 12].

Последующий спад интереса инвесторов к новым технологиям многие восприняли как "технологический пат" или "инновационную паузу". Однако уже к 2015 году на смену несостоявшимся технологическим прорывам (нанотехнологической революции) пришел новый концепт - четвертой промышленной революции (цифровой экономики или более узко "Индустрии 4.0" ) [13]. Нельзя не отметить, что "четвертая промышленная революция" - весьма размытый концепт, имеющий все признаки лоббистского проекта [14], как в свое время NBRIC-конвергенция. При этом упор в новой революции делается на кардинальную трансформацию сферы услуг: начиная от финансовых и транспортных и заканчивая сферой рекреации и домашнего хозяйства. Однако с чем же, по сути, мы имеем дело-с формированием очередной новой экономики или долгожданного нового технологического уклада, с революционным изменением бизнес-процессов или с очередным чисто финансовым явлением, призванным стимулировать фондовые рынки? Или речь идет о попытке создать новые обширные рынки для отрасли ИКТ и микроэлектроники?

Если рассмотреть динамику и структуру расходов ведущих мировых компаний на НИОКР по основным технологическим направлениям, то можно заметить, что посткризисного восстановительного бума инвестиций в те технологии, которые могли бы стать базовыми для потенциального шестого технологического уклада, пока не наблюдается. Приоритетными направлениями финансирования со стороны корпораций по-прежнему остаются "традиционные" технологии пятого технологического уклада, связанные с микроэлектроникой и ИКТ, которые продолжают генерировать основной объем выручки, а также обеспечивают наибольший уровень рентабельности.

Согласно целому ряду исследований, сектор ИКТ продолжает оставаться ключевым источником инноваций в большинстве экономик стран ОЭСР. Расходы на исследования в области информационных технологий (ИТ) составляют наибольшую часть расходов

* Термином "Индустрия 4.0" (Industry 4.0) обычно обозначают развитие широкого круга перспективных производственных технологий (робототехника, аддитивное производство и пр.), которые могут лечь в основу четвертой промышленной революции. 
компаний (25\% от общего числа расходов на НИОКР, выделяемых бизнесом). Это от 0,2 до 0,4\% от ВВП по странам ОЭСР. В Финляндии, Израиле, Корее и США расходы на сектор ИТ составляют от 40 до 50\% от общих затрат частного бизнеса на НИОКР, что составляет от 0,6 до более чем 1,8\% ВВП [15]. Таким образом, именно этот сектор характеризуется наибольшей исследовательской интенсивностью, что также подтверждается количеством инновационных продуктов и патентов, регистрируемых в этой области.

В табл.1 показаны приоритетные направления финансирования НИОКР в странах-лидерах по объемам валовых затрат на НИОКР со стороны частных компаний по данным ОЭСР на 2013 год.

Как видно из табл.1, ИКТ-услуги и радиоэлектронное оборудование находятся в тройке приоритетов финансирования НИОКР всех без исключения ключевых стран ОЭСР, включая Францию (где соответствующее направление отражено в сегменте финансовые и коммерческие услуги). Если сравнивать два всплеска бурного развития ИКТ в 2000-2003 годах и в 2010-2013 годах, то общая патентная активность за 10 лет выросла на 66\%. При этом весьма показательно, что основной рост патентной активности наблюдался в таких областях, как разработка новых видов взаимодействия человека и компьютера (с 4 до 8\%) и в области новых технологий мобильной связи (с 4 до 7\%) [15].

Наиболее репрезентативную по состоянию на конец 2016 года информацию о расходах на НИОКР дает исследование The Economics of Industrial Research \& Innovation [16]. В нем рассматривается отчетность 2500 крупнейших в мире по объемам инвестиций в НИОКР компаний (в рейтинг попадают компании, тратящие больше 20 млн долл. в год на НИОКР). На эти 2500 компаний приходится порядка 800 млрд долл. расходов на НИОКР ежегодно, то есть почти 45\% от общемировых расходов на НИОКР и порядка $90 \%$ от всех корпоративных расходов на НИОКР. Именно расходы этих корпораций лучше всего иллюстрируют наиболее востребованные направления финансирования науки и технических разработок. В табл. 2

Таблица 1. Приоритеты инвестирования в НИОКР по направлениям в ключевых странах по данным ОЭСР на 2013 год. Источник: [15]

\begin{tabular}{|c|c|c|c|c|}
\hline & \multicolumn{3}{|c|}{ Доля от общих частных инвестиций в НИОКР } & \multirow{2}{*}{$\begin{array}{c}\text { Общие затраты } \\
\text { компаний на } \\
\text { НИОКР, } \\
\text { \% от ВВП }\end{array}$} \\
\hline & 1-е место & 2-е место & 3-е место & \\
\hline \multirow[t]{2}{*}{ США } & ИКТ-оборудование & $\begin{array}{c}\text { Химическая } \\
\text { промышленность }\end{array}$ & иКТ-услуги & \multirow[t]{2}{*}{1,90} \\
\hline & $21,53 \%$ & $20,83 \%$ & $19,21 \%$ & \\
\hline \multirow[t]{2}{*}{ Япония } & $\begin{array}{l}\text { Транспортное } \\
\text { оборудование }\end{array}$ & ИКТ-оборудование & $\begin{array}{c}\text { Химическая } \\
\text { промышленность }\end{array}$ & \multirow[t]{2}{*}{2,64} \\
\hline & $24,55 \%$ & $22,95 \%$ & $21,11 \%$ & \\
\hline \multirow[t]{2}{*}{ Корея } & ИКТ-оборудование & $\begin{array}{l}\text { Транспортное } \\
\text { оборудование }\end{array}$ & $\begin{array}{c}\text { Химическая } \\
\text { промышленность }\end{array}$ & \multirow[t]{2}{*}{3,26} \\
\hline & $51,66 \%$ & $12,91 \%$ & $10,90 \%$ & \\
\hline \multirow[t]{2}{*}{ Британия } & Услуги по НИОКР & $\begin{array}{l}\text { Транспортное } \\
\text { оборудование }\end{array}$ & ИКТ-услуги & \multirow[t]{2}{*}{1,03} \\
\hline & $27,41 \%$ & $16,87 \%$ & $14,15 \%$ & \\
\hline \multirow[t]{2}{*}{ ФРГ } & $\begin{array}{l}\text { Транспортное } \\
\text { оборудование }\end{array}$ & $\begin{array}{c}\text { Химическая } \\
\text { промышленность }\end{array}$ & ИКТ-оборудование & \multirow[t]{2}{*}{1,95} \\
\hline & $37,26 \%$ & $16,59 \%$ & $13,74 \%$ & \\
\hline \multirow[t]{2}{*}{ Франция } & $\begin{array}{c}\text { Финансовые } \\
\text { и коммерческие услуги }\end{array}$ & $\begin{array}{l}\text { Транспортное } \\
\text { оборудование }\end{array}$ & Услуги по НИОКР & \multirow[t]{2}{*}{1,44} \\
\hline & $18,28 \%$ & $16,74 \%$ & $12,30 \%$ & \\
\hline
\end{tabular}


представлены ключевые показатели деятельности этих 2500 компаний за 2015 год, сгруппированные нами по видам деятельности.

Как видно из таблицы, более трети всех крупнейших инновационных компаний в мире работают именно в сфере производства радиоэлектроники и ИКТ или оказания ИКТ-услуг. На них работает более 21\% от общего числа занятых в инновационно-активных компаниях, они генерируют более $20 \%$ выручки и осуществляют более 36\% всех инвестиций в НИОКР. Необходимо отметить, что компании, занятые в секторе "фармакология и биотехнологии", также отличаются высоким уровнем наукоемкости, однако по масштабам самого сектора (количеству компаний, занятых работников и объемам производства) серьезно уступают сектору, объединяющему ИКТ и радиоэлектронику. Наукоотдача в сфере электронных производств и оказания ИКТ-услуг также намного выше. На каждый вложенный в НИКОР доллар затрат компании из радиоэлектронного сектора и ИКТ получают в среднем на 40\% больше дохода, чем компании, специализирующиеся на фармакологии и биотехнологиях.

Можно заключить, что такие новые прорывные технологии, как некоторые биотехнологии или нанотехнологии, требуют постоянно растущих и при этом весьма значительных расходов на НИОКР при низкой материальной отдаче, вследствие чего они малопривлекательны для инвесторов. Поэтому, чтобы создать условия для формирования финансовой, а затем и технологической инфраструктуры, необходимой для их успешного развития и превращения в эффективный механизм стимулирования экономического роста, сначала предстоит обеспечить продление механизмов роста на основе уже имеющихся технологий,

Таблица 2. Ключевые показатели крупнейших по объемам затрат на НИОКР частных компаний, сгруппированные по видам деятельности за 2015 год. Источник: [16], расчеты авторов

\begin{tabular}{|c|c|c|c|c|c|c|}
\hline Отраслевая группа & $\begin{array}{c}\text { Кол-во } \\
\text { компа- } \\
\text { ний }\end{array}$ & $\begin{array}{c}\text { Кол-во } \\
\text { занятых, } \\
\text { тыс. чел }\end{array}$ & $\begin{array}{c}\text { Выручка, } \\
\text { млрд } \\
\text { долл. }\end{array}$ & $\begin{array}{c}\text { Рентабель- } \\
\text { ность, } \\
\%\end{array}$ & $\begin{array}{c}\text { Затраты на } \\
\text { НИОКР, } \\
\text { млрд долл. }\end{array}$ & $\begin{array}{c}\text { Наукоем- } \\
\text { кость, } \\
\%\end{array}$ \\
\hline Радиоэлектроника + ИКТ, в том числе: & 834 & 10286,5 & 3987,5 & 12,4 & 278,9 & 7,0 \\
\hline $\begin{array}{l}\text { Компьютерная техника } \\
\text { и оборудование }\end{array}$ & 298 & 2966,3 & 1407,9 & 14,7 & 123,0 & 8,7 \\
\hline $\begin{array}{l}\text { Программное обеспечение } \\
\text { и ИТ-услуги }\end{array}$ & 278 & 2623,0 & 802,8 & 15,4 & 87,8 & 10,9 \\
\hline $\begin{array}{l}\text { Электроника и электронное } \\
\text { оборудование }\end{array}$ & 228 & 3697,7 & 1209,6 & 8,0 & 58,0 & 4,8 \\
\hline Фиксированная телефонная связь & 17 & 883,6 & 532,6 & 11,4 & 9,4 & 1,8 \\
\hline Мобильная связь & 13 & 115,9 & 34,6 & 15,7 & 0,7 & 2,0 \\
\hline Фармакология и биотехнологии & 369 & 2038,9 & 934,5 & 19,2 & 146,6 & 15,7 \\
\hline Производство автомобилей и запчастей & 156 & 6703,1 & 2729,5 & 6,0 & 119,4 & 4,4 \\
\hline Промышленный инжиниринг & 199 & 2914,6 & 916,1 & 7,4 & 30,5 & 3,3 \\
\hline Химическая промышленность & 126 & 1429,8 & 859,6 & 10,6 & 25,7 & 3,0 \\
\hline $\begin{array}{l}\text { Аэрокосмическая и оборонная } \\
\text { промышленности }\end{array}$ & 53 & 1538,8 & 542,2 & 8,5 & 23,3 & 4,3 \\
\hline Другие секторы промышленности & 86 & 2077,2 & 723,6 & 6,8 & 21,8 & 3,0 \\
\hline $\begin{array}{l}\text { Услуги здравоохранения и медицинское } \\
\text { оборудование }\end{array}$ & 98 & 1143,3 & 438,1 & 9,0 & 16,4 & 3,8 \\
\hline Товары для досуга и отдыха & 38 & 582,3 & 268,4 & 6,5 & 16,0 & 6,0 \\
\hline Остальные виды деятельности & 541 & 18711,4 & 8185,9 & 5,7 & 92,1 & 1,1 \\
\hline Всего в рейтинге & 2500 & 47425,9 & 19585,4 & 8,6 & 770,7 & 3,9 \\
\hline
\end{tabular}


то есть на базе микроэлектроники и ИКТ. Однако это уже не может произойти просто за счет экстенсивного роста "первичных" ИКТ-услуг, таких как мобильная связь или предоставление доступа к Интернету, но только путем превращения ИКТ и основанных на них новых моделей производства и оказания услуг во всеобъемлющую инфраструктуру. Именно это, по сути, и предлагает нам концепт четвертой промышленной революции (цифровой экономики), который провозглашает необходимость скорейшего встраивания в новый перспективный тренд.

Действительно, в основе данного проекта-углубленное развитие глобальной цифровой инфраструктуры ("цифровой экосистемы") для последующей автоматизации и роботизации на ее основе целых отраслей промышленности и сферы услуг. Именно такая "экосистема" может стать средой для формирования новых производственных технологий, включая внедрение киберфизических систем и Интернета вещей, развития новых электронных способов ведения бизнеса, а также для кардинальной модернизации таких социально значимых сфер как медицина и образование. Таким образом, провозвестники новой технологической революции видят в ИКТ новую универсальную платформу для решения различных экономических и социальных вызовов. Между тем, пока это лишь идея, а что мы имеем в реальности? Ведь, по сути, речь идет о масштабном распространении тех технологий, которые развиваются уже довольно давно, таких как, например, робототехника. Проблема в том, что эти технологии до сих пор не смогли создать новые массовые производства и рынки. Отсюда возникает вопрос, какие объективные процессы привели к идее о том, что новая технологическая революция неизбежно случится и будет носить именно цифровой, а не иной характер?

Прежде всего, следует отметить, что по своей формулировке построение цифровой экономики весьма напоминает те процессы, которые происходили во второй половине 1990-х - начале 2000-х годов в связи с развитием ИКТ. Речь идет о создании новых высокотехнологичных производств и услуг, для которых микроэлектроника и Интернет станут базовыми условиями развития. Это, в свою очередь, должно оказывать мощное обратное воздействие на аппаратную составляющую ИКТ. Таким образом, новый импульс для своего развития радиоэлектроника может получить именно в рамках глобального тренда на построение "цифровой экономики", которая в расширенном понимании продвигается как глобальная парадигма ускорения экономического роста за счет косвенных эффектов от внедрения ИКТ во всех сферах человеческой жизни. Причем, по нашему мнению, речь идет не только и не столько о новых технологиях, которые стимулируют новую волну роста, а о создании новых массовых рынков потребления микроэлектроники.

Например, организация производственных процессов на основе ИКТ-инфраструктуры подразумевает внедрение компьютеров и программного обеспечения для совершенствования управления различными участками производства, оснащение станками с программным обеспечением и роботизацию, которая позволит полностью автоматизировать некоторые производственные звенья и транспортировку, а также развитие аддитивного производства, в том числе 3D-печати, промышленного Интернета и т.д. Создание цифровой инфраструктуры для внедрения и распространения такого рода инноваций в сфере материального производства приведет к формированию нового устойчивого рынка сбыта для самой широкой номенклатуры радиоэлектронной продукции, а также предпосылки для его долгосрочного роста. Мы привели в пример только производство, а ведь новая цифровая революция подразумевает цифровизацию всех сфер жизни.

Мы полагаем, что концепция "четвертой промышленной революции" имеет основной целью дальнейшую коммерциализацию уже имеющихся ИКТ, контролируемых несколькими транснациональными системообразующими корпорациями. Следует отметить, что рынки массовых изделий на основе ИКТ формируют, а следовательно, и контролируют разработчики и производители базовых микроэлектронных компонентов. Именно микропроцессоры определяют архитектуру и функциональные возможности конечной продукции, обуславливают ее номенклатуру, а также функциональные возможности вторичных микроэлектронных компонентов и других продуктов ИКТ.

Такие компании, как Intel, IBM, Sony, Samsung, уже реализовали бизнес-модель, при которой инвестиции в генерацию инноваций и нововведений приносят основную долю прибыли и обеспечивают контроль над соответствующим сектором рынка. При этом в рамках НИОКР ими разрабатываются новые базовые микроэлектронные компоненты, рассчитанные на производство на новом технологическом оборудовании и по новым технологическим стандартам. В совокупности с контролем над существенной долей высокотехнологичных производств и рынков, высокой прибылью от продажи инновационных изделий это создает возможности для очень быстрого оборота капитала, что позволяет за короткий период переходить к следующему инновационному циклу [17]. Таким образом, формируется механизм, 
обеспечивающий транснациональным корпорациям в сфере ИКТ постоянное поддержание монопольного положения на рынке и получения "технологической ренты" [18]. Однако, чтобы обеспечить воспроизводство такого механизма инновационного развития и получения ренты, необходимо, чтобы инновационные продукты принципиально имели крайне короткий жизненный цикл. Между тем, в условиях затяжного кризиса мировой экономики, падения спроса в странах Запада и перепроизводства продукции короткий жизненный цикл товаров оборачивается существенными проблемами. По нашему мнению, "четвертая промышленная революция" (цифровая экономика) - это фактически попытка мощными лоббистскими усилиями создать возможности для колоссального расширения рынка сбыта для продукции индустрии ИКТ и микроэлектроники.

Таким образом, речь идет о том, чтобы сохранить имеющуюся модель технологической ренты и пребывания на верхнем сегменте производственного передела - инновационность ИКТ-компаний, которую мы видели на примере табл.1 и 2, имеет целью отнюдь не технологический прогресс и создание новых технологий - прежде всего, это успешный и высокоэффективный механизм удержания технологической ренты. Соответственно, технологии в других сферах не могут "выстрелить", потому что там не сложилось такого механизма. Для создания инновационного продукта, имеющего значительно более длительный жизненный цикл и требующего заметно больше времени на создание и разработку (биотех, нанотех), постоянно требуется дополнительное финансирование, которое сложно привлечь в условиях стагнации мировой экономики. Именно поэтому они не могут стать основой нового технологического уклада и способствовать возобновлению высоких темпов роста мировой экономики.

\section{ЛИТЕРАТУРА}

1. Cameron J., Siegmann K. A. Why did mainstream economics miss the crisis? The role of epistemological and methodological blinkers // On the Horizon. 2012. Vol. 20. № 3. P. 164-171.

2. Куиггин Дж. Зомби-экономика. Как мертвые идеи продолжают блуждать среди нас. - М.: Издательский дом ВШЭ. 2016. 272 с.

3. Кошовец О.Б. Почему господствующая экономическая теория прозевала кризис: о роли онтологических барьеров // Вестник Института экономики РАН. 2017. № 3. C. 18-34.

4. ICT for Economic Growth: A Dynamic Ecosystem Driving the Global Recovery. World Economic Forum Annual Meeting Report. 2009. 11 p.
5. Ustundag A., Cevikcan E. Industry 4.0. Managing the Digital Transformation. - Springer Verlag, 2017. 293 p.

6. Глазьев С. Ю. Теория долгосрочного технико-экономического развития. - М.: ВлаДар, 1993. 310 с.

7. Ruttan V.W. Is War Necessary for Economic Growth? Military Procurement and Technology Development.N.Y.: Oxford University Press, 2006. 219 p.

8. Draper W.H. The startup game: Inside the partnership between venture capitalists and entrepreneurs. - N.Y.: Palgrave Macmillan, 2012. 272 p.

9. Carlaw K.I., Lipsey R. G., Webb R. The Past, Present and Future of the GPT-Driven Modern ICT revolution. Final (Blue) Report Industry - Canada. 27 March 2007.

10. Cassidy J. Dot.con: How America lost its mind and money in the internet era.- N.Y.: Perennial, 2003. 416 p.

11. Kelleher K. Here's Why Nobody's Talking About Nanotech Anymore // Time, viewed October 9, 2015.

12. Кошовец О.Б. Ганичев Н. А. Нанотехнологии и формирование шестого технологического уклада: ожидания и реальность // Проблемы прогнозирования. 2017. № 4. C. 44-52.

13. Deep Shift Technology Tipping Points and Societal Impact. World Economic Forum survey Report. September 2015. 44 p.

14. Шваб К. Четвертая промышленная революция.М.: Издательство "Э", 2017. 208 с.

15. OECD Science, Technology and Industry Scoreboard 2015: Innovation for growth and society. - Paris: OECD Publishing, 2015. $260 \mathrm{p}$.

16. The 2016 EU Industrial R\&D Investment Scoreboard.Luxembourg: Publications Office of the European Union, 2016. 107 p.

17. Бетелин В., Велихов Е. Развитие российского сегмента мировой ИТ-индустрии. Возможные сценарии // ЭЛЕКТРОНИКА: Наука, Технология, Бизнес. 2007. № 2. С. 4-11.

18. Бендиков М.А., Фролов И.э. Высокотехнологичный сектор промышленности России: состояние, тенденции, механизмы инновационного развития.М: Наука, 2007. 583 C. 